\title{
Sustainable packaging in footwear industry: Case study of PUMA
}

\section{Lucie Sara Zavodna *(D), Lucie Trejtnarova **(D)}

\author{
* College of Polytechnics Jihlava, Department of Economic Studies, Jihlava, Czech Republic \\ ** Tomas Bata University in Zlin, Faculty of Multi-Media Communication, Zlin, Czech Republic
}

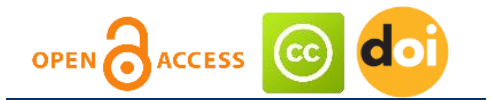

Article history:

Received: January 01, 2021

1st Revision: February 12, 2021

Accepted: April 09, 2021

JEL classification:
Q01
Q56
M31

DOI:

10.14254/jems.2021.6-1.2

\begin{abstract}
Purpose. Modern companies are more focused on the life cycle of their products, so it comes also with sustainable packaging of products. Some companies do this on their own initiative, others because of customer's pressure. There are already several experiments, where companies introduced packaging that can be disposed of in an environmentally friendly way or reused. The main goal of the paper is to describe case study of sustainable packaging in the footwear industry. Main findings and implications. Even big producers of shoes are facing troubles with sustainable packaging solutions. The case study shows why PUMA abandoned the new sustainable packaging of shoes. After trying sustainable packaging, PUMA returned to the classic cardboard box in 2015 .
\end{abstract}

Keywords: footwear industry, shoes, packaging, sustainability, packaging redesign, environment.

\section{Introduction}

From all generated household waste, nearly $65 \%$ consists of packaging materials according to calculations made by McDonough and Braungart (2013). Packaging is often underrated by most customers, while it fulfils essential functions. Most packaging functions would have served their time, as soon as a consumer has picked up the packaging (Robertson, 2012, Zhang \& Zhao, 2012).

Packaging of shoes is going through a redesigning process mostly by bigger companies. It is because of modern trends of sustainability, green design or circular economy. According to Wang and Yang (2008) green packaging design is a designing packaging method which aims to reduce, reuse, and recycle the materials used to make packaging. The results of Rokka and Uusitalo (2008) research show that most consumers prefer green packaging and prefer products which are packaged with eco-friendly packaging. This indicates a change of the consumers' mindset in the way of the ethical side as well as producer awareness towards the environment is becoming one of the factors that determine consumer. Moreover, in designing green packaging is important to improve the efficiency of natural resource usage, and utilize all packaging components to be useful not only as a medium to protect and sell but also to add value beyond its basic functions (Liu \& Zhang, 2010). 
Packaging has always been a part of the consumption process and is an elementary component of globalisation (Siegle, 2010). Packaging's traditional function is to protect the product to avoid generating losses along the supply chain to the final consumer (Williams et al., 2008). Moreover, authors such as Jonson (2000), Garcia-Arca and Prado-Prado (2008) or Bramklev (2009) associate three basic functions to packaging: commercial, logistic and environmental. Especially the last one is the reason why companies such as PUMA and Nike are in search of changing the standard boxes to different material and design packaging. There are three different levels to be considered in relation to packaging's hierarchical structure: primary packaging (consumer packaging; packaging which is in contact with the product), secondary packaging (designed to contain several primary packages) and tertiary packaging (used when a number of primary or secondary packages are assembled on a pallet or roll container) (Jönson, 2000). Moreover, the Consumer Goods Forum has made a broader definition of packaging system functions. These functions are (1) to protect the product, (2) to promote the product, (3) to provide information on the product, usage, health and safety, disposal, etc. (4) to enable the convenient transportation and usage of the product, (5) to allow the unitisation of the product through the supply chain, (6) to support the efficient handling of the product throughout the supply chain (Novak, 2016).

Paper and cardboard are one of the oldest materials which still cover the largest proportion of packaging. Although paper cardboard may be easy to recycle, the production of these materials are still harmful to the environment - with large amounts of carbon emissions and energy required to process and transport. For shoes, paper is used as stuffing paper or filler paper to preserve the shape of the shoe, wrapping paper to protect the footwear in a pair box, pair box to protect the finished pair of shoes before delivery to the customer and transport packaging for transporting the finished products. Some companies even use two cardboard boxes to send shoes to the final customer (Sutanto, 2018, Novak, 2016).

Another substance in shoe's boxes is silica gel. Silica gel is a desiccant, a substance that absorbs moisture, which makes these packets perfect for keeping things extremely dry and moisture-free. Silica gel itself is non-toxic, but can have additives of some dangerous chemicals (e.g. dimethyl fumarate) and cobalt dichloride. Because of the excessive risk of the presence of dangerous substances inside the silica gel, the new anti-mould stickers (e.g. Micro-Pak) became popular, usually glued to the top of the shoe-box (Novak, 2016).

Magnier et al. (2016) define sustainability in packaging as the effort to reduce the product footprint through altering the product's packaging. Companies, who do research in sustainable packaging solutions, have several possibilities. New approaches are focused on (1) reusable returnable packaging possibilities (after use of the product, it is returned to the shop, from where it is returned to the manufacturer and re-used) or (2) new materials for packaging (f.e. biodegradable or recycled). The example of the first approach is RePack (Amsterdam, Hamburg, Helsinki, USA). This packaging solution can be owned and managed by the user, owned by the user and managed by a third party, rented by the user from a third party pooling company, transferred between multiple end users and recycling companies, or exchanged between members of a co-op or association.

The second option is packaging made from materials healthy throughout the life cycle. This solution optimizes the use of renewable or recycled source materials or is manufactured using clean production technologies (Sustainable Packaging Coalition, 2011). All approaches towards sustainable packaging are intended to benefit the environment, minimise the carbon footprint of man-made packaging waste and also to cut down costs (The Economist, 2007). The second approach is represented by Econyl (Italy), Adaptive Packaging (PUMA) or Freitag (Switzerland). PUMA's Adaptive packaging for example expands to fit around the product placed inside, and has a built-in lifespan that means it eventually self-degrades, leaving no physical waste (Winston, 2018).

\section{Materials and methods}

First, a literature search was conducted on the topic of the paper. Web of science (WOS) searching was realized upon keyword searches, whereas two logical search strings were used "shoe" AND "packaging". The selection of the designated keywords was made based on the aim of the paper. Searching was limited to English written journal papers only. Selected keywords were searched within the WOS Topics, which includes title, abstract, author keywords, and Keywords Plus. The data were collected using the PRISMA 2009 method (Moher et al., 2009), a method often used in medical science (Knobloch, 2011) to provide verified preferred reporting items for preparing systematic reviews and meta-analyses.

Selected articles were then analysed by bibliometrics in R-tool, which is an open-source tool for quantitative research in scientometrics and bibliometrics (Aria \& Cuccurullo, 2017). All together 89 documents from the period 1991 - 2019 with 284 authors. From those were 59 articles and 30 
proceeding papers. Most relevant sources were in journal Papier (4 documents). Most relevant authors were Paik K.W. (3 docs), Schuwerk W. (3 docs) and Tamiru A. (3 docs).

The following was chosen as the main research question: Which company has already implemented a sustainable strategy for packaging shoes? Other research questions were: What material did the company use? What was the impact? Was is successful?

To fulfill the paper's aim, the case study method has been chosen. It is a research approach in which one or a few instances of a phenomenon are studied. If the knowledge of the examined case is critical, it is essential to have reliable data. In this respect, the case was chosen using the data resulting from Life Cycle Assessment of different shoe packaging designs, also data from company's own assessment.

\section{PUMA case study of sustainable shoe packaging}

PUMA is a globally well-known company producing sportswear clothes and shoes. Their mission is to be the most desirable and sustainable sport lifestyle company in the world. That is why PUMA issues a Sustainability report every year. This case study focuses on the specific project of sustainable shoe packaging, which was introduced in 2010 and removed from the market in 2015.

The company partnered with Fuseproject's Yves Béhar in San Francisco to reinvent the shoebox. New solution for shoe packaging was called the "Clever Little Bag". The unique packaging system eliminated the shoebox entirely. Instead, it consisted of a die-cut sheet of ink-free, thin-gauge recycled paperboard that tapers to form four walls, which were then held in place by a $20 \%$, nonwoven polypropylene bag (Welbel, 2011). One of the basic ideas was that, unlike the cardboard boxes, there would be no need for additional plastic carrier bags for the reusable shoe bags.

The clever little bag consisted of a non-woven polypropylene bag and corrugated "bone" providing stability to the design and ensuring at the same time that there is no contact between the shoes. The design of the bag (see Fig. 1) was different due to the missing middle layer the bag weight was potentially $25 \%$ lower compared to the standard box. Therefore the weight of the bag was approximately $0.02 \mathrm{~kg}$. The same corrugated material as for the current design $(100 \%$ recycled material) was used for corrugated "bone" and weighed approximately $0.082 \mathrm{~kg}$ (PE Americas, 2010).

Figure 1: New solution for shoes packaging

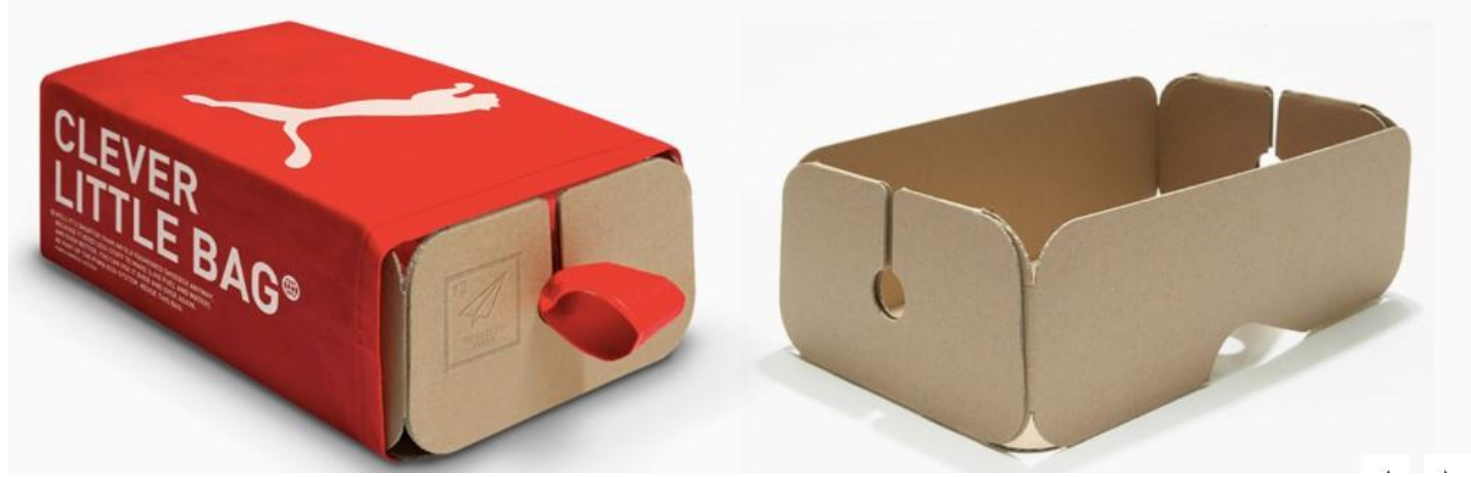

Source: Fuseproject, 2020

The cardboard structure was cut from one flat piece of material and had no additional printing or assembly, thus it could be returned to the stream faster and more efficiently. The structure was created with four walls that taper in to allow for secured stacking. The bag was non-woven which means less work and waste (it was stitched with heat). It was made to protect the shoes from dust and dirt in the warehouse and during shipping (see Fig. 2 for storage system). The "clever little bag" could also be repurposed for creative reuse. The bag was made of non-woven polyester consisting of polypropylene, and eventually is also recyclable (Fuseproject, 2020). 
Figure 2: The clever little bag - storage system

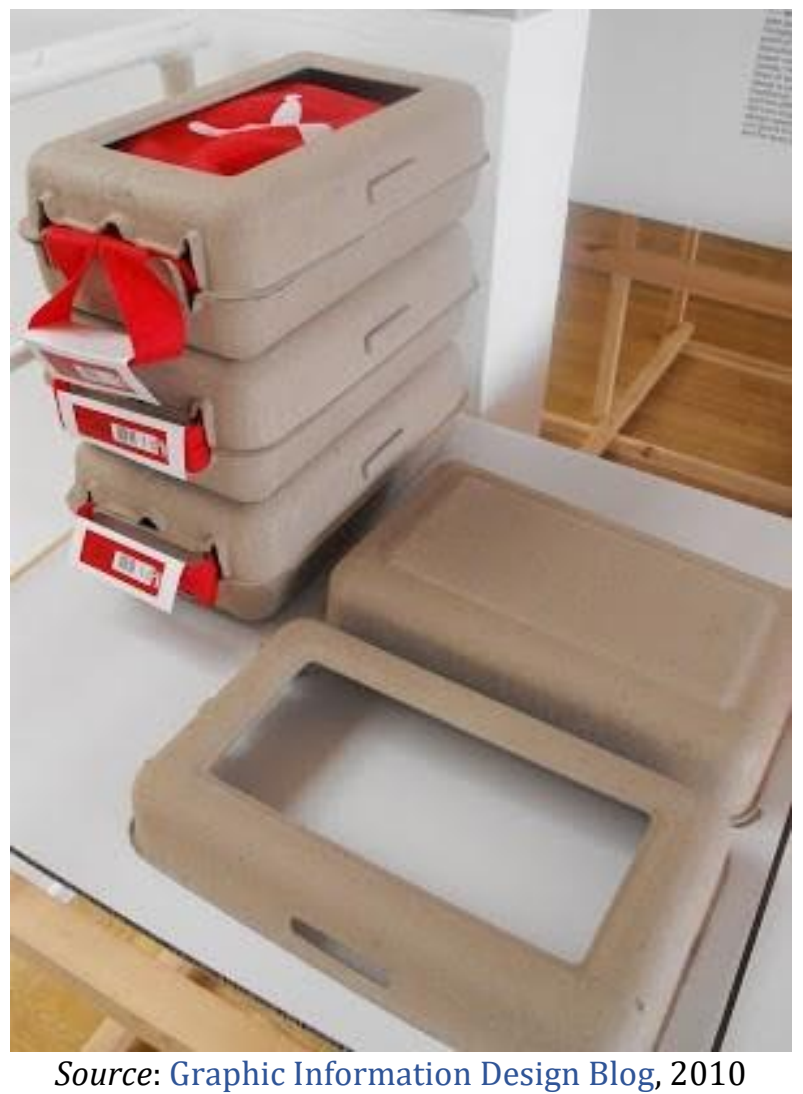

In Table 1 there is data from a life-cycle assessment of classic red box (cardboard) compared to the new Clever little bag. Clever little bag is lighter by $0,156 \mathrm{~kg}$ per unit. Also, there are savings in water, energy and diesel consumption on the manufacturing level by more than $60 \%$ per year. That means approximately 8.580 tons less paper was consumed, 20 million Mega joules of electricity saved, 1 million litres less of fuel oil used and 1 million litres of water saved. During transport 500,000 litres of diesel was saved and lastly, due to the replacement of traditional shopping bags with the lighter built-in bag the difference in weight could save up to 275 tons of plastic (PUMA, 2010). As PUMA stated in the sustainability report (PUMA Sustainability Report 2012), shoes delivered in Clever Little Bags have increased sales to $82 \%$. That led to a substantial decrease in cardboard usage of 5400 tons in comparison to conventional shoe boxes.

\begin{tabular}{lcccc} 
Table 1: Potential savings Clever little bag to standard red shoe box \\
\cline { 2 - 5 } & \multicolumn{4}{c}{ Related to 55 million units per year } \\
\cline { 2 - 5 } & $\begin{array}{c}\text { Clever Little } \\
\text { Bag }\end{array}$ & $\begin{array}{c}\text { Red shoe } \\
\text { box }\end{array}$ & $\begin{array}{c}\text { Savings per } \\
\text { unit }\end{array}$ & $\begin{array}{c}\text { Annual } \\
\text { savings }\end{array}$ \\
\hline Paper used & 0.082 & 0.238 & $0.156 \mathrm{Kg}$ & 8580 tons \\
Power for paper production & 0.179 & 0.546 & $0.367 \mathrm{MJ}$ & $20 \mathrm{Mio}$ Mj \\
$\begin{array}{l}\text { Fuel Oil for paper / box production } \\
\text { Water consumed for paper }\end{array}$ & 0.008 & 0.026 & 0.018 litres & 1.0 Mio litres \\
production & 0.010 & 0.031 & 0.021 litres & 1.1 Mio litres \\
$\begin{array}{l}\text { Water consumed for unit } \\
\text { manufacturing }\end{array}$ & 0.0003 & 0.022 & 0.022 litres & 1.2 Mio litres \\
Diesel for transportation & & & & \\
\hline
\end{tabular}

Source: (PE Americas, 2010).

Nevertheless, PUMA returned to the classic cardboard box in 2015. Company said it was because the bags weren't as easy to stack as cardboard boxes and after trying on the shoes, consumers were not as easy to put back in the eco-bags as they are in cardboard boxes. Customers as well as retail partners repeatedly reported issues regarding difficulties in the handling of the Clever Little Bag in the retail environment, which led to the development of a new, more conventional footwear packaging. Instead, the autumn and winter 2015 collection was delivered in new green shoe boxes (see Fig. 3). To uphold high environmental standards, the new PUMA shoebox was made from over 95\% recycled and fully FSC certified material (PUMA Sustainability Report, 2014). 


\section{Figure 3: New PUMA box made from 95\% recycled material}

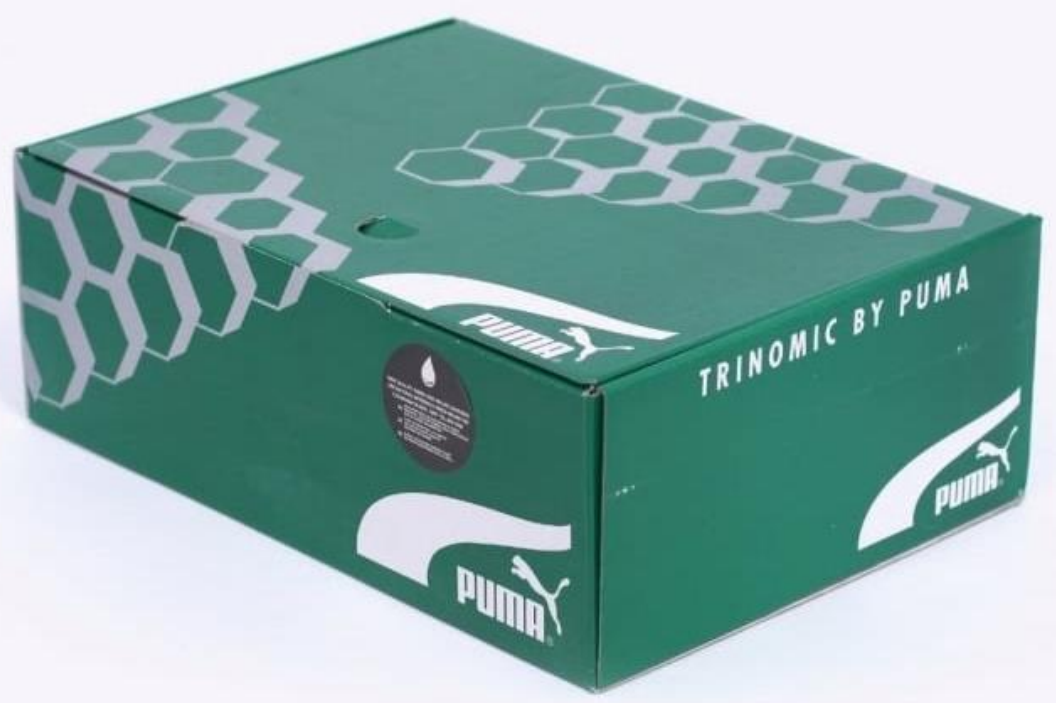

Source: Triads, 2020

\section{Other sustainable shoe packaging solutions}

PUMA is not the only company who tries to find a new solution for shoe boxes. Another example is company Viupax, who decided to reinvent the shoe box in 2017 and minimize space needed for transportation of shoes (see Fig. 4). The new solution by Viupax is an eco-friendly box designed by Matadog Design from Greece. It uses up to 57\% less paper and needs an average area of $0,25 \mathrm{~m} 2$. It saves up to $50 \%$ of space in the container. Moreover, it could be used as a shipping box. For this idea Viupax won 3 international design awards in 2018 (Viupax, 2020).

Viupax offers two options of licensing: (1) A volume-based fee, that is available for a multimillion box annual order and (2) an annual lump sum free. Boxes are produced by Viupax's supplier. Special boxes are designed for children's shoes - they can be easily converted into toys.

Figure 4: New solution for shoes packaging made by Viupax

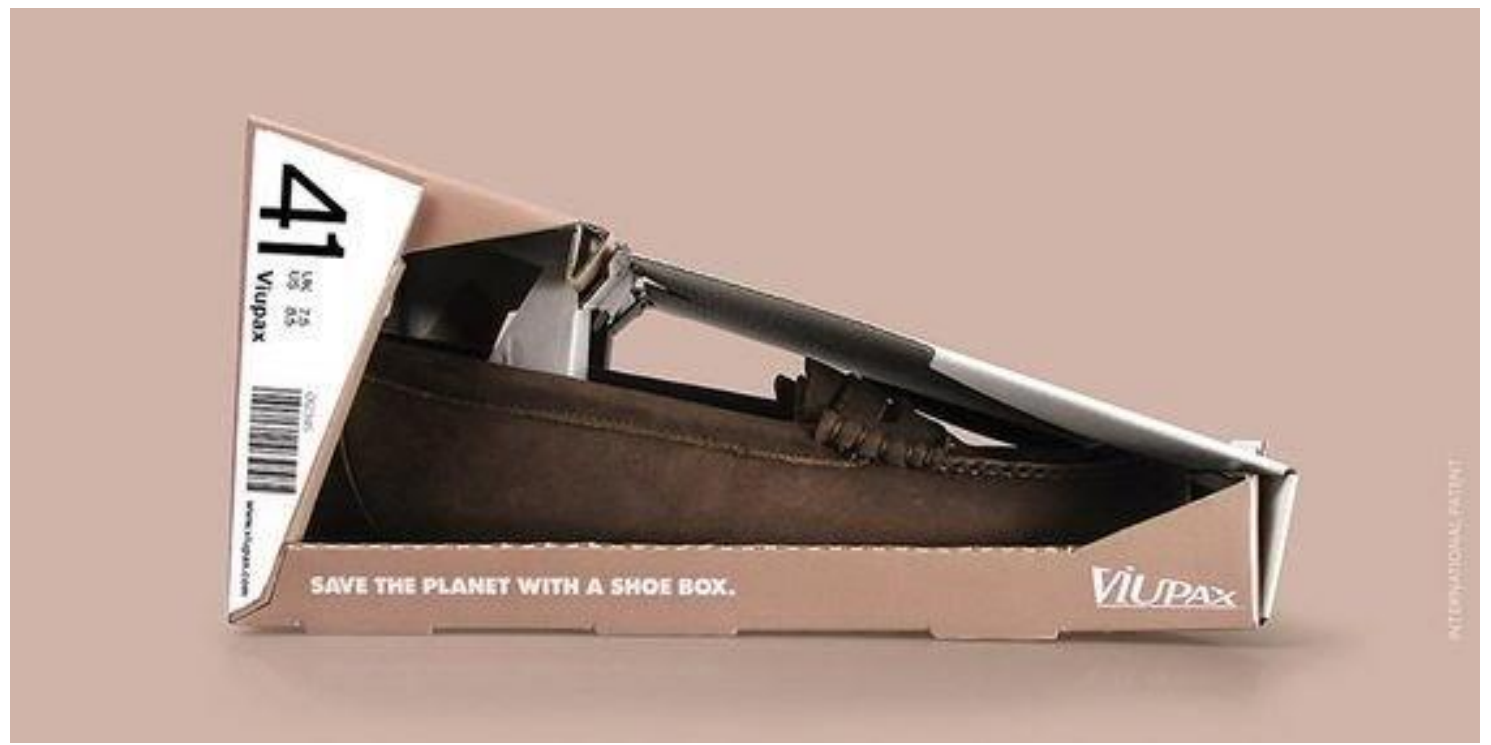

Source: Viupax, 2020

\section{Discussion and conclusion}

Packaging in the footwear industry is an important topic. But there are not so many new and green solutions. It could be questioned the way, how companies transport empty space in boxes, but also excessive materials. Through the research we found out that there is a focus on sustainable shoe 
or clothes materials, but little companies do about packaging itself nor ways to transport those products.

To have the example of PUMA in mind, we could clearly state that a sustainable option is not always the right solution for customers or retail. Still it is right to rethink the way companies use to do standard packaging. The possibilities are reduction of packaging material, reduction of transported empty space, reduction of transport distance, usage of biodegradable materials, other use of packaging (f.e. as a toy for children), etc.

\section{Citation information}

Zavodna, L. S., \& Trejtnarova, L. (2021). Sustainable packaging in footwear industry: Case study of PUMA. Economics, Management and Sustainability, 6(1), 27-33. doi:10.14254/jems.2021.61.2

\section{Reference}

Aria, M., \& Cuccurullo, C. (2017). Bibliometrix: An R-tool for comprehensive science mapping analysis. Journal of Informetrics, 11(4), 959-975.

Bramklev, C. (2009). On a proposal for a generic package development process. Packaging Technology and Science, 22(3), 171-186. https://doi.org/10.1002/pts.850

Fuseproject. (2020, December 10). https://www.fuseproject.com/work/puma-clever-little-bag

Garcia-Arca, J. \& Prado-Prado (2008). Packaging design model from supply chain approach. Supply Chain Management, 13(5), 375-380.

Graphic Information Design Blog. (2010). Sustainable Futures Exhibition: Design Museum. http://gdes2012tutor.blogspot.com/2010/04/sustainable-futures-exhibition-design.html

Jonson, G. (2000). Packaging Technology for the Logistician. Lund University, Lund.

Knobloch, K., Yoon, U., \& Vogt, P. M. (2011). Preferred reporting items for systematic reviews and meta-analyses (PRISMA) statement and publication bias. Journal of Cranio-Maxillofacial Surgery, 39(2), 91-92.

Liu, Y. X., \& Zhang, Y. (2010). Study on universal packaging design and its environmental utility based on the theory of "Make the Best Use of Everything". Packaging Engineering, 16 (003).

Magnier, L., Schoormans, J.P.L., \& Mugge, R. (2016). Judging a product by its cover: Packaging sustainability and perceptions of quality in food products. Food Quality and Preference, 53, 132-142.

McDonough, W., \& Braungart, M. (2013). The upcycle: Beyond sustainability, designing for abundance. New York: North Point Press.

Moher, D., Liberati, A., Tetzlaff, J., Altman, D. G., \& the PRISMA Group (2009). Preferred reporting items for systematic reviews and meta-analyses: The PRISMA statement. Annals of Internal Medicine, 151(4), 264-269."

Novak, B. (2016). UNIT 9 - Sustainable packaging for footwear. https://www.step2sustainability.eu/docs/Unit9.pdf

PE Americas. (2010). Life Cycle Assessment of different shoe packaging design for PUMA.

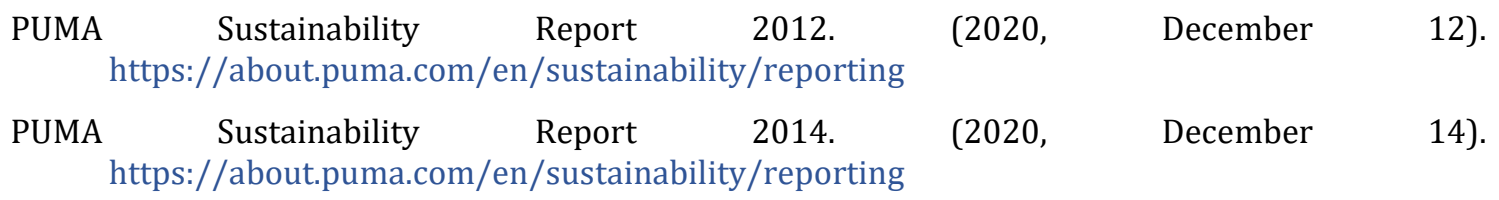

PUMA. (2010). Puma's new packaging and distribution system to save more than $60 \%$ of paper and water annually. https://about.puma.com/en/newsroom/corporate-news/2010/04-132010-pumas-new-packaging-and-distribution-system

Robertson, G. L. (2012). Food packaging: Principles and practice (3rd ed.): CRC press.

Rokka, J., \& Uusitalo, L. (2008). Preference for green packaging in consumer product choices-do consumers care?. International Journal of Consumer Studies, 32(5), 516-525. 
Siegle, L. (2010). Recycle: The essential guide. London: Black Dog.

Sustainable Packaging Coalition. (2011). Definition of sustainable packaging. Virginia: GreenBlue.

Sutanto, S.M. (2018). Clever Little Bag"Green Packaging Inovation from Puma. Visual Communication Design Journal, 3(1), 1-12.

The Consumer Goods Forum. (2010). A Global Language for Packaging and Sustainability. Paris.

The Economist (2007, 07.06.). The truth about recycling, 383, 24.

Triads (2020, December 5). https://www.triads.co.uk/triads-mens-c1/footwear-c24/trainersc211/puma-r698-green-box-pack-trainers-amazon-green-p70505

Viupax (2020, December 1). http://viupax.com/sustainable-packaging/eco-friendly-shoe-box/

Wang, L., \& Yang, M. (2008). Green Packaging Design on the Principle of 3R. Packaging Engineering, 2(058).

Welbel, J. (2011). Puma's "Clever Little Bag". Packaging strategies. https://www.packagingstrategies.com/articles/92042-puma-s-clever-little-bag

Williams, H., Wikstrom, F. \& Lofgren, M. (2008). A life cycle perspective on environmental effects of customer focused packaging development. Journal of Cleaner Production, 7, 853-859.

Winston, A. (2018). Puma and MIT Design Lab envision a future of self-adapting, performanceenhancing sportswear. Dezeen. https://www.dezeen.com/2018/05/24/mit-media-labpuma-future-sportswear-design/

Zhang, G., \& Zhao, Z. (2012). Green packaging management of logistics enterprises. Physics Procedia, $24,900-905$

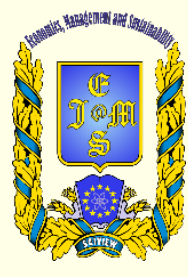

(c) 2016-2021, Economics, Management and Sustainability. All rights reserved.

This open access article is distributed under a Creative Commons Attribution (CC-BY) 4.0 license.

You are free to:

Share - copy and redistribute

purpose, even commercially.

The licensor cannot revoke these freedoms as long as you follow the license terms.

Under the following terms:

must give appropriate credit, provide a link to the license, and indicate if changes were made.

You may do so in any reasonable manner, but not in any way that suggests the licensor endorses you or your use.

No additional restrictions

You may not apply legal terms or technological measures that legally restrict others from doing anything the license permits.

Economics, Management and Sustainability (ISSN: 2520-6303) is published by Scientific Publishing House "CSR",

Poland, EU and Scientific Publishing House "SciView", Poland

Publishing with JEMS ensures:

- Immediate, universal access to your article on publication

- High visibility and discoverability via the JEMS website

- Rapid publication

- Guaranteed legacy preservation of your article

- Discounts and waivers for authors in developing regions

Submit your manuscript to a JEMS at http://jems.sciview.net or submit.jems@sciview.net

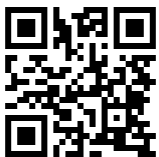

